\title{
Knowledge Management Strategies to Improve Learning and Growth in Creative Industries: A Framework Model
}

\author{
Alexandra Sinta Wahjudewanti' ${ }^{1}$, Jann Hidajat Tjakraatmaja ${ }^{2}$, Yudo Anggoro ${ }^{3}$ \\ ${ }^{1,2,3}$ School of Business and Management, Institut Teknologi Bandung, Indonesia
}

\section{Abstract}

The aim of this study is to propose a framework model to capture the knowledge management (KM) process and KM enablers and their connection to improving learning and growth in creative industries. This study is a literature review that analyses several articles related to KM and creative industries. Field observations were conducted at two creative industries to verify the literature review results. This review explores several studies of KM enablers and KM processes to identify KM's relationship with organizational performance. Organizational performance can be measured from several perspectives, one of which is the tangible perspective of learning and growth. The framework model comprises three interrelated concepts of KM and performance: $K M$ enablers, KM processes, and learning and growth as an intangible type of performance. Further study is needed to identify the types of KM enablers and KM processes to obtain a better understanding of how to improve the performance of creative industries. This study is limited to knowledge management in creative industries. Studies of KM strategies in creative industries are limited, including in Indonesia. Previous studies identify the relationship between KM implementation and improving tangible performance measurements, such as financial and customer performance. This study contributes to our knowledge of implementing $K M$ to improve intangible performance in creative industries.
Keywords

knowledge management; creative industries, innovation; learning and growth; performance

\section{Introduction}

Creative industries were first introduced in the 1990s, emerging in 1994 when Australia launched the Creative Nation report. The term "creative industries" gained wider exposure in 1997, when policymakers at the United Kingdom's Department of Culture, Media and Sport (DCMS) set up the Creative Industries Task Force (UNCTAD, 2010). According to the DCMS (2001), creative industries involve those activities that have their origin in an individual's creativity, skill, and talent and have the potential for wealth and job creation through the generation and exploitation of intellectual property. Indonesia established Creative Economy Agency in 2015 to develop creative economy. Creative industries contribute to Gross Domestic Product (GDP) in Indonesia. The number is increasing every year. 
Table 1. GDP from Creative Economy in Indonesia (Bekraf Report, 2018)

\begin{tabular}{|c|c|}
\hline Year & $\begin{array}{c}\text { GDP Creative Economy } \\
\text { (IDR Trillion) }\end{array}$ \\
\hline 2010 & 525.96 \\
\hline 2011 & 581.54 \\
\hline 2012 & 638.39 \\
\hline 2013 & 708.27 \\
\hline 2014 & 784.87 \\
\hline 2015 & 852.56 \\
\hline 2016 & 922.59 \\
\hline
\end{tabular}

As creative industries contribute to a country's economic growth, their personnel will be involved in producing knowledge products. Thus, they should be considered knowledge workers. Peter Drucker originated the concept of knowledge workers, who are considered an organization's most valuable asset. Knowledge worker productivity is determined by several factors, one of which is that knowledge workers need to manage themselves and have autonomy. In addition, continuing innovation has to be part of knowledge workers' work, tasks, and responsibilities. Knowledge workers require both continuous learning and continuous teaching and must produce quality outputs (Drucker, 1999). Organizations can develop knowledge workers by implementing knowledge management (KM).

According to Yani in Syardiansyah (2020) performance is a result of work achieved by a person in carrying out the tasks assigned to him based on skill, experience and sincerity as well as time. However according to Kasmir (2016) that performance is the result of work and work behavior of a person in a period, usually 1 year. Then the performance can be measured by the ability to complete the tasks and responsibilities given. This means that in work contains elements of the standard that achievement must be met, so, for those who reach the standards set means good performance.

Performance management systems are set to aid organizations in order to design and organize what they should do, deliver precise and proper feedforward and feedback on how they are doing. And inspire remedial behavior as and when needed (Anthony \& Govindarajan in Mansaray, 2020). Knowledge workers with good productivity are expected to improve enterprise performance. Kaplan and Norton (1996) measure an organization's performance across four linked perspectives: (1) financial, (2) customer, (3) internal business processes, and (4) learning and growth. This research examines implementing knowledge management to improve performance in creative industries, using learning and growth to measure performance.

This study's objective is to develop a framework model through a comprehensive academic literature review of research on KM strategies to improve learning and growth in creative industries. Two field observations were also conducted to confirm the literature review. The proposed framework models the relationship between KM processes, KM enablers, and learning and growth. The remainder of this paper is organized as follows. Section two discusses the literature related to the research objective. Section three describes the method adopted to tackle the research problem and the proposed framework model is presented in section four. The last section presents conclusions and the study's recommendations. 


\section{Review of Literature}

This study is a systematic literature review to propose a framework model related to the use of $\mathrm{KM}$ in creative industries to improve organizational performance. The performance studied is tangible performance that is the learning and growth. This section will discuss about the literature which is used as the background of this study. The literature review covers creative industries, KM, and learning and growth as one performance perspective

\subsection{Creative Industries}

Creative industries became popular in the 1990s when policymakers at the United Kingdom's DCMS set up the Creative Industries Task Force (UNCTAD, 2010). According to the DCMS (2001), creative industries are those activities that have their origin in an individual's creativity, skill, and talent and have the potential for wealth and job creation by generating and exploiting intellectual property.

Because creative industries have become important for local economies, it is necessary to improve their performance. KM in creative industries will play an important role in increasing organization performance (Latilla et al., 2018). It is important to apply $\mathrm{KM}$ in creative industries for several reasons. For example, implementing KM can avoid the knowledge attrition caused by staff turnover (Durst and Wilhelm, 2011). Furthermore, $\mathrm{KM}$ involves management's exploitation and development of knowledge assets with the aim of enhancing organization performance (Lee et al., 2014).

\subsection{Knowledge Management}

A high-level definition describes knowledge management (KM) as the discipline of managing an organization's processes of creating, organizing, and sharing knowledge. KM should be implemented in every organization to maintain the knowledge that exists in that organization. Desouza (2006) found several peculiarities in KM implementation in small and medium enterprises (SMEs), including knowledge loss. When employees leave an organization, they take knowledge out the door. To avoid this, KM should be applied in SMEs to maintain organizational knowledge. Another peculiarity is people-centered KM, where technology is considered in the background. In people-centered KM, knowledge is created, shared, transferred, and applied via people-based mechanisms. Knowledge generated is immediately put into practice, rather than being stored in some obscure technology artifact, such as a database.

\subsection{Knowledge Management Process}

The KM process consists of several steps. A number of researchers have agreed to define KM as a strategy of KM processes, which include knowledge creation, storage, and application (Durst and Wilhelm, 2011; Lee et al., 2014). The KM process involves other processes, such as KM transfer and KM sharing (Lee, 2014; O'Connor, 2016). Furthermore, KM can be explained as a process of creating, capturing, and using knowledge to enhance organizational performance (Evangelista et al., 2010). 
Table 2. Knowledge Management Processes from Previous Studies

\begin{tabular}{|l|l|}
\hline \multicolumn{1}{|c|}{ Author } & \multicolumn{1}{c|}{ KM Processes } \\
\hline $\begin{array}{l}\text { Evangelista } \text { et al. } \\
(2010)\end{array}$ & $\begin{array}{l}\text { Process of creating, capturing, and using knowledge to enhance } \\
\text { organizational performance }\end{array}$ \\
\hline Durst et al. (2011) & $\begin{array}{l}\text { KM can be divided into five core activities: identification, creation, } \\
\text { storage, dissemination and use of knowledge (Comite European de } \\
\text { Normalisation - CEN) }\end{array}$ \\
\hline Heavin et al. (2012) & Knowledge activities: acquire, codify, store, maintain, transfer, create. \\
\hline Lee et al. (2014) & $\begin{array}{l}\text { KM processes: knowledge acquisition, creation and generation, } \\
\text { application and utilization, codification and storing, and transferring } \\
\text { and sharing }\end{array}$ \\
\hline $\begin{array}{l}\text { O'Connor } \text { et al. } \\
\text { (2016 }\end{array}$ & $\begin{array}{l}\text { The processes and structures provided to support different knowledge } \\
\text { processes, such as transfer, storage, and creation. }\end{array}$ \\
\hline
\end{tabular}

Although there are more studies on an integrated model of $\mathrm{KM}$ processes, this literature review focuses on KM implementation in creative industries or small and medium size enterprises. It analyzes the KM processes summarized from the literature, as shown in Table I. The KM processes in this study include knowledge identification, storage, sharing and application.

\subsection{KM Enablers}

Various KM enablers have been discussed in previous studies; Table II summarizes the factors affecting KM found in previous research. Several metrics have been proposed to measure KM. For example, several factors of organizational culture affect KM, including leadership and management support (Lee et al., 2014) and trust (Lee and Choi, 2003).

Table 3. Factors affecting KM

\begin{tabular}{|l|l|}
\hline \multicolumn{1}{|c|}{ Author } & \multicolumn{1}{|c|}{ Factors Affecting KM } \\
\hline Lee and Choi (2003) & $\begin{array}{l}\text { Organizational culture (collaboration, trust, and care), } \\
\text { organizational structure, people and technology (IT support). }\end{array}$ \\
\hline Lehner et al. (2010) & $\begin{array}{l}\text { Top management, personality, personnel development, meta- } \\
\text { communication of KM, KM goal system, KM process, } \\
\text { delegation/participation, staff member motivation, social } \\
\text { nets/relationships, a knowledge encouraging corporate } \\
\text { culture, application systems, system, KMS. }\end{array}$ \\
\hline Lee et al. (2014) & $\begin{array}{l}\text { Culture, management leadership and support, organizational } \\
\text { infrastructure, strategy, resources, human resource } \\
\text { management. }\end{array}$ \\
\hline
\end{tabular}

Another KM enabler that affects an organization's KM implementation is its people. As part of the people factor, intellectual capital is important in KM (Lee and Choi, 2003; Lee et al., 2014). Motivation also affects KM implementation in an organization. If the people in an organization are motivated, KM will be applied more effectively (Lehner et al., 2010). Finally, technology, such as IT and application systems, also enables KM (Lee and Choi, 2003; Lehner et al., 2010). Computer usage helps create, share, store and use the knowledge in an organization. This study focuses on three factors that enable KM: organizational culture, people, and technology.

\subsection{Learning and Growth}


Implementing KM is expected to improve an organization's performance. There are four perspectives of performance: financial, customer, internal business processes, and learning and growth. Kaplan and Norton (2004) explained organizational performance by dividing it into two categories: tangible (previous) and intangible (future). Lee and Choi (2003) analyzed the relationship among KM enablers, KM processes, and organizational performance. Organizational performance is assessed using global output measures such as market share, profitability, growth rate, and business size, all of which are categorized as tangible. Lee and Choi (2003) found that KM strategies influence organizational performance through organizational creativity.

Learning and growth identifies the infrastructure that an organization must build to create long-term growth and improvement (Kaplan and Norton, 1996). Organizational learning and growth describes how people, technology, and the organizational climate combine to support a strategy (Kaplan and Norton, 2004). This perspective views organizational performance through the lenses of human capital, infrastructure, technology, culture, and other capacities that are keys to breakthrough performance. The objective in the learning and growth perspective is to provide an infrastructure that will enable achieving ambitious objectives in the other three perspectives. The objectives in the learning and growth perspective are the drivers for achieving excellent outcomes in the other three perspectives. The enablers for learning and growth primarily come from three sources: employees, systems, and organizational alignment. Strategies for superior performance will generally require significant investments in people, systems, and processes that build organizational capabilities. Therefore, learning and growth is an intangible asset used to achieve organizational targets.

Kaplan and Norton (2004) explained that learning and growth as an intangible asset has become decisive for sustainable value creation. The learning and growth perspective includes the objectives and measures for three intangible components that are essential for implementing any strategy:

1. Human capital: Human capital represents the availability of the employee skills, talent, and know-how required to perform the internal processes that are critical for the strategy's success.

2. Information capital: Information capital, consisting of systems, databases, libraries, and networks, makes information and knowledge available to the organization.

3. Organization capital: Organization capital provides the ability to integrate so that individual intangible human and information capital assets, as well as tangible physical and financial assets, are not only aligned with the strategy but are integrated and work together to achieve the organization's strategic objectives.

The learning and growth perspective that drives improvements in managing operations has several objectives (Kaplan and Norton, 2004):

1. Develop quality management and process improvement skills.

The original definition of quality for Total Quality Management (TQM) programs was "conformance to specifications." Managers strive to produce each item and deliver each service based on the specifications established for that product or service. The definition of quality shifted from conforming to specifications to meeting customer's expectations. If targeted customers' expectations for product or service delivery performance exceed previously established specifications, then the specifications need to be raised. Perfect quality can be defined as follows: a company's operations should strive to have its customers experience zero defects in its products and services. The ideal customer experience is a product that meets customer specifications and is suitable for the customer's immediate use. 
2. Acquire technology that facilitates process improvement and customer satisfaction.

Technology plays a critical role in improving operational performance. Many repetitive, labor-intensive processes can be automated to provide lower cost, more consistent quality, and more rapid processing times.

3. Develop a culture of continuous improvement.

Employees must have an intense focus on continuous process improvement and consistent delivery of services to customers. The culture must encourage generating new ideas and solutions for process improvement and sharing those ideas with other workgroups in the organization.

The learning and growth as organization's performance is related to relationships with customers, employees and their skills, knowledge, and an organizational culture aimed at innovation, problem solving, and general business improvement. By constantly renewing knowledge, it is possible to create and add value, thus increasing the commercial transfer of skills and knowledge in applied experience (Jelenic, 2011). This study focuses on the learning and growth factors that affect product quality and organizational innovation performed.

\section{Research Methods}

This research is a systematic literature review regarding the use of $\mathrm{KM}$ in creative industries to improve organizational performance. The review was conducted in three stages: planning the review, conducting the review, and reporting and dissemination (Tranfield et al., 2003). Table IV presents a summary of the main activities in each stage.

The first stage is planning the review. An exploratory search of the literature for the main related topics was conducted, following the guidelines of Galvan and Galvan (2017). A study was conducted of the topics related to KM enablers and KM processes. The relationship between $\mathrm{KM}$ enablers and $\mathrm{KM}$ strategies for improving organizational performance was constructed. An important result of this stage is the preliminary version of the research question. Another result is the definition of the criteria used for filtering the paper sample. The papers were selected based on topics related to KM implementation and refined in creative industries.

Table 4. Summary of Main Activities (adapted from Transfield et al., 2003)

\begin{tabular}{|c|c|c|}
\hline $\begin{array}{c}\text { Stage 1 } \\
\text { Planning the Review }\end{array}$ & $\begin{array}{c}\text { Stage } 2 \\
\text { Conducting the Review }\end{array}$ & $\begin{array}{c}\text { Stage } 3 \\
\text { Reporting and Dissemination }\end{array}$ \\
\hline $\begin{array}{l}\text { Phase } 0 \text { - Identify the need for } \\
\text { a review } \\
\text { - Explore literature to search } \\
\text { for KM and creative } \\
\text { industries } \\
\text { Phase } 1 \text { - Prepare proposal for } \\
\text { a review } \\
\text { - Propose preliminary research } \\
\text { question } \\
\text { - Define criteria for paper } \\
\text { sample selection. } \\
\text { Phase } 2 \text { - Develop a review } \\
\text { protocol } \\
\text { - Data analysis plan }\end{array}$ & $\begin{array}{l}\text { Phase } 3 \text { - Identify research } \\
\text { Phase } 4 \text { - Select studies: } \\
\text { Phase } 5 \text { - Study quality } \\
\text { assessment } \\
\text { Phase } 6 \text { - Data extraction and } \\
\text { monitoring progress } \\
\text { - Data analysis: } \\
\text { ○ Title and abstract } \\
\text { ○ Full paper } \\
\circ \text { Focused reading } \\
\text { Phase } 7 \text { - Data synthesis }\end{array}$ & $\begin{array}{l}\text { Phase } 8 \text { - Prepare report and } \\
\text { recommendations } \\
\text { - Initial draft of introduction } \\
\text { - Simultaneous data analysis } \\
\text { - Propose a conceptual } \\
\quad \text { framework } \\
\text { Phase } 9 \text { - Getting evidence } \\
\text { into practice }\end{array}$ \\
\hline
\end{tabular}


The second stage suggested by Tranfield et al. (2003) is to conduct the review itself from the data collected; several search engines were used find related articles, including Mendeley, ProQuest, Publish or Perish, and Google Scholar. The primary selection criteria were that the articles discussed KM in creative industries. All articles were required to be Scopus indexed papers published between 2010 and 2020. The following filters were used: "knowledge management" and "creative industry" or "creative economy." The final sample consists of 90 articles, highlighting that there are still few studies on KM implementation in creative industries.

Several papers were eliminated due to several reasons. First, the articles selected shall be published in Scopus Indexed journals. Then the abstracts were read carefully to ensure that the study was conducted for creative industries and covered KM implementation. Finally, 24 articles were selected for further analysis.

The data analysis was conducted by reading the full text of each paper with a focus on the abstract, research method, and conclusion sections. The information was organized in a spreadsheet to identify KM enablers and KM processes in each article. In addition, papers discussing KM implementation to improve organizational performance were noted in the spreadsheet. The last stage of the research, reporting and disseminating (Tranfield et al., 2003), was conducted simultaneously with the data analysis. A conceptual framework was proposed based on the data obtained from previous research and literature reviews.

\section{Results and Discussion}

This section describes the data obtained from the sample papers. After an overview of the paper sample, integrating the KM processes, KM enablers, and learning and growth are more deeply discussed. Field observations are also presented to verify several literature review results.

\subsection{General Overview: Literature and Topics}

Descriptive Statistics of the paper sample data were used to obtain an overview of the literature analyzed. Figure 1 presents the yearly evolution of papers published on KM in creative industries from 2010 to 2020. As shown, there are still few publications discussing KM in creative industries, but the number increased in 2018 and 2019. As this study is being conducted in the third quarter of 2020, the number of publications may still be increasing.

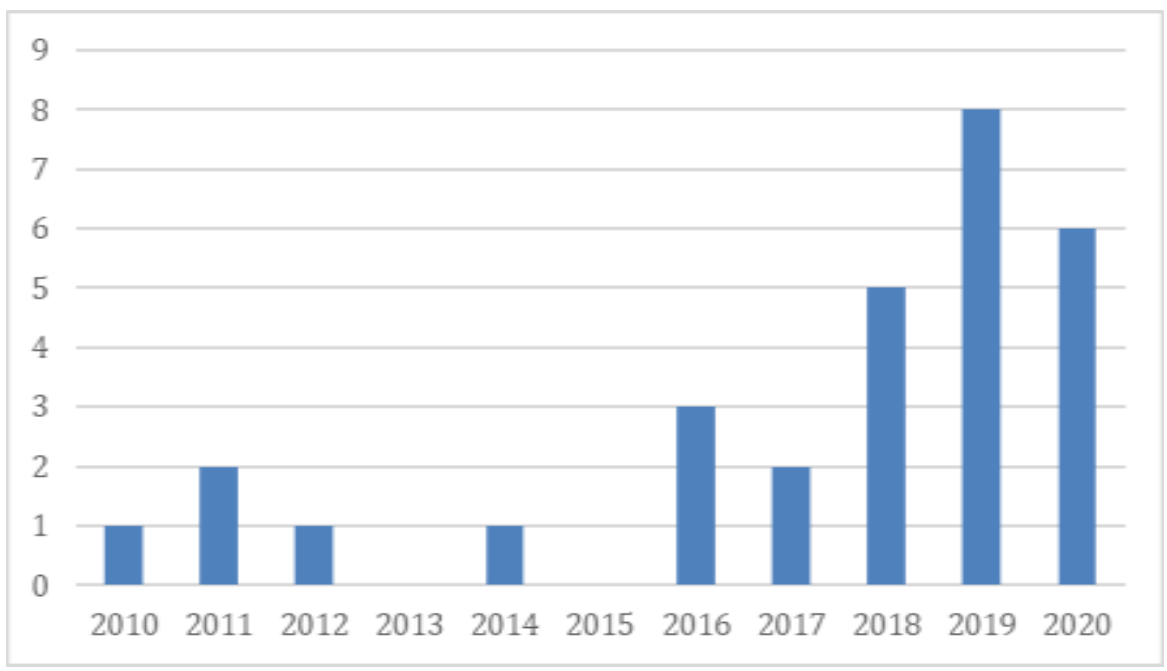

Figure 1. Yearly Evolution 
Table 5 presents the articles published in Scopus Indexed journals from 2010 to 2020 with the topics discussed in this study. Based on several academic databases, various types of research have been conducted in creative industries. However, only a few types of research in creative industries discuss KM implementation; they are categorized as KM enablers, KM processes, learning and growth, and innovation. KM processes explain KM activities as knowledge identification, knowledge storage, knowledge sharing, and knowledge application (Lee et al., 2015). Some previous studies have discussed KM processes in creative industries, but more studies focus on knowledge sharing, which includes knowledge transfer and training (Adhiatma et al., 2020; Andraini et al., 2019; Bashouri and Duncan, 2014; Bettiol et al., 2012; Cruz et al., 2019; Gateau and Simon, 2016; Hussein et al., 2016; Latilla et al., 2018; Millar et al., 2016; Radomska et al., 2019; Stejskal and Hajek, 2019; Tassabehji et al., 2019). There are few previous research studies about knowledge storage. Bashori and Duncan (2014) emphasized that knowledge needs to be captured, stored, and shared to benefit the people in an organization.

Referring to the previous discussion about $\mathrm{KM}$ in creative industries, $\mathrm{KM}$ enablers, and $\mathrm{KM}$ processes are the foundation for learning and growth. KM enablers are the mechanisms an organization uses to develop its knowledge and stimulate knowledge creation within the organization, as well as its sharing and protection (Yeh et al., 2006). Allameh et al. (2011) identified three categories of KM enablers-technology, structure, and culture - while Yeh et al. (2006) identified four-strategies and leadership, corporate culture, people, and technology. In this research, KM enablers will be measured using three elements: organizational culture, people, and technology.

Table 5. List of publications focused on KM in creative industries

\begin{tabular}{|c|c|c|c|c|c|c|c|c|c|c|}
\hline \multirow[b]{2}{*}{ References } & \multicolumn{3}{|c|}{ KM Enablers } & \multicolumn{4}{|c|}{ KM Strategies } & \multicolumn{2}{|c|}{ Performance } & \multirow[b]{2}{*}{ 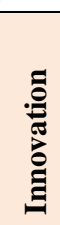 } \\
\hline & 壹 & ä & 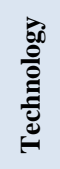 & 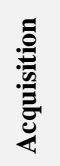 & 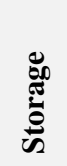 & 竎 & 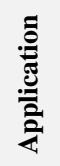 & 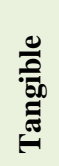 & 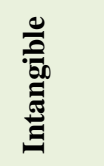 & \\
\hline Adhiatma et al., 2020 & & & $\mathrm{v}$ & & & $\mathrm{v}$ & & & & \\
\hline Andraiani et al., 2019 & & $\mathrm{v}$ & $\mathrm{v}$ & & & $\mathrm{v}$ & & $\mathrm{v}$ & & \\
\hline Bashouri and Duncan, 2014 & & & $\mathrm{v}$ & & $\mathrm{v}$ & $\mathrm{v}$ & & & & \\
\hline Bettiol et al., 2012 & & & & & & $\mathrm{v}$ & $\mathrm{v}$ & & & \\
\hline Castagna et al., 2020 & & & $\mathrm{v}$ & & & & & $\mathrm{v}$ & & \\
\hline Cruz et al., 2019 & & & & & & $\mathrm{v}$ & & & & $\mathrm{v}$ \\
\hline Ferraris et al., 2020 & & & & & & & $\mathrm{v}$ & & & $\mathrm{v}$ \\
\hline Gateau and Simon, 2016 & & & & $\mathrm{v}$ & & $\mathrm{v}$ & & & & $\mathrm{v}$ \\
\hline Ginting, 2020 & & $\mathrm{~V}$ & & $\mathrm{v}$ & & & $\mathrm{v}$ & & & \\
\hline Hotho and Champion, 2011 & & $\mathrm{~V}$ & & & & & & & & $\mathrm{v}$ \\
\hline Hussein et al., 2016 & & & & & & $\mathrm{v}$ & & & & \\
\hline Hussein et al., 2019 & & & & $\mathrm{v}$ & & $\mathrm{v}$ & & & & $\mathrm{v}$ \\
\hline Latilla et al., 2018 & & & & & & $\mathrm{v}$ & & & & \\
\hline Latilla et al., 2019 & & & & & & $\mathrm{v}$ & & & & \\
\hline Long, 2017 & & & & & & $\mathrm{v}$ & & & & \\
\hline Ma et al., 2018 & & & $\mathrm{~V}$ & & & & & & & $\mathrm{v}$ \\
\hline Mayasari and Chandra, 2020 & & & & & & & & & & \\
\hline Millar et al., 2016 & $\mathrm{v}$ & & & $\mathrm{v}$ & & $\mathrm{v}$ & & & & $\mathrm{v}$ \\
\hline Othman and Khalil, 2018 & & $\mathrm{v}$ & & & & & & & & $\mathrm{v}$ \\
\hline Radomska et al., 2019 & $\mathrm{v}$ & $\mathrm{v}$ & & & & $\mathrm{v}$ & & & & \\
\hline Ruiz et al., 2018 & & & & $\mathrm{v}$ & & & & & & \\
\hline Seidel, 2011 & & & $\mathrm{v}$ & & & & & & & \\
\hline Stejskal and Hajek, 2019 & & & & $\mathrm{v}$ & & $\mathrm{v}$ & $\mathrm{v}$ & & & $\mathrm{v}$ \\
\hline Tassabehji et al., 2019 & $\mathrm{v}$ & $\mathrm{v}$ & $\mathrm{v}$ & & & $\mathrm{v}$ & & & & $\mathrm{v}$ \\
\hline
\end{tabular}


Organizational culture as a KM enabler consists of organizational goals, leadership, and employees' trust in management. Milar et al. (2016) studied leadership and knowledge management through formal knowledge strategies in knowledge-intensive organizations. Radomska et al. (2019) examined the role of trust in cooperation, as well as its role in shaping internal relationships in companies operating in the creative industries.

As one of the elements of KM enablers, people can be measured in several ways, which include their intellectual capital, collaboration among an organization's members, and motivation. Hotho and Chapion (2011) discussed changing people management practices in creative industries and found that management and worker perspectives about innovation as strategic change and the central people management practices required to support this differ significantly. Technology can be measured based on the usage of management information systems (MIS) or information and communications technology (ICT). MIS and ICT have become important KM enablers in this digital era (Ma et al., 2016; Adhiatma et al., 2020; Castagna et al., 2020; Seidel, 2011).

KM processes involve several steps. Allameh et al. (2011) presented the KM cycle as six different processes: knowledge creation, knowledge capture, knowledge organization, knowledge storage, knowledge dissemination, and knowledge application. Wee and Chua (2013) explained that KM processes can be divided into several activities: knowledge creation, knowledge sharing, and knowledge reuse. This research combines KM strategies from previous research. First, an organization should identify or create knowledge. The knowledge then should be stored to allow it to be reused. Knowledge sharing is another part of the KM strategy and provides other members of an organization with the tacit knowledge that some personnel use in the workplace. Knowledge application allows the knowledge to be used and reused. This can allow improvement in the learning process as well as lead to better performance.

\subsection{General Overview: Literature and Topics}

The relationship between $\mathrm{KM}$ enablers and $\mathrm{KM}$ processes is described in the following proposition:

Proposition 1: KM enablers positively influence KM strategies.

Learning and growth identifies the infrastructure that an organization must build to create long-term growth and improvement (Kaplan and Norton, 1996). The learning and growth perspective views organizational performance through the lenses of human capital, infrastructure, technology, culture, and other capacities that are keys to breakthrough performance. The objectives in the learning and growth perspective are the drivers for achieving excellent outcomes in the other three perspectives. The enablers for learning and growth primarily come from three sources: employees, systems, and organizational alignment. Strategies for superior performance will generally require significant investments in people, systems, and processes that build organizational capabilities. Learning and growth influences product quality and innovation.

Latilla et al. (2018) conducted research related to KM implementation in creative industries to provide a literature review regarding the relationship between $\mathrm{KM}$, knowledge transfer, and organizational performance. This research also analyses how KM and knowledge transfer between arts and craft organizations helps increase performance and enhances the value of knowledge workers' activities. The KM process aims to support innovation and encourage the free flow of ideas throughout the company. This process increases a company's value because it increases efficiency and effectiveness in the relationship between all resources and innovation (Jelenic, 2011). 
Proposition 2 explains the relationship between $\mathrm{KM}$ processes and learning and growth.

Proposition 2: KM processes positively influence learning and growth.

KM enablers, which include organizational culture, people, and technology, affect the performance of creative industries. Hussein et al. (2016) studied technology in creative industries and found that an information system is necessary for business creativity to absorb and disseminate new information and knowledge.

The proposed relationship between KM enablers and learning and growth is stated as follows:

Proposition 3: KM enablers positively influence learning and growth.

This research aims to develop a conceptual framework model to study KM implementation to improve learning and growth in creative industries. Several KM enablers, including culture, people, technology, and processes, are investigated. The KM strategies of knowledge identification, knowledge storage, knowledge sharing, knowledge application, and knowledge development are studied. The proposed framework model is illustrated in Figure 2.

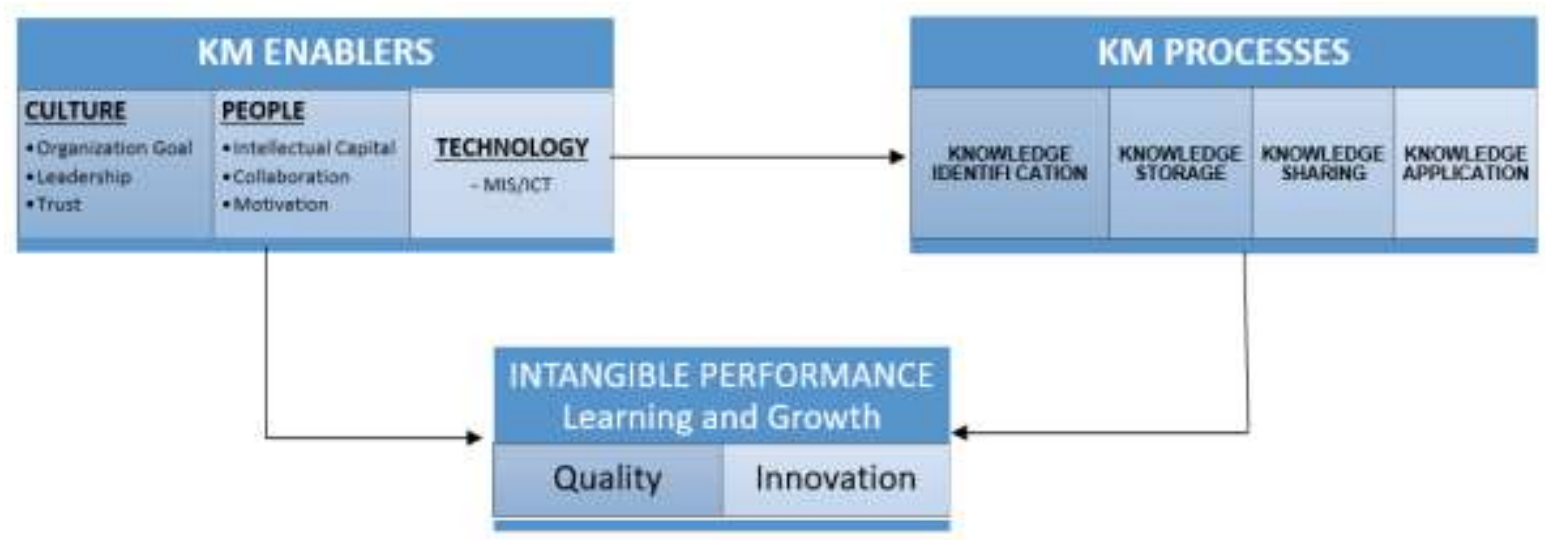

Figure 2. A proposed framework model

The proposed framework model suggests that KM enablers and KM processes promote learning and growth in creative industries. In addition, KM enablers affect KM processes.

\subsection{Preliminary Findings}

Two interviews were conducted to test the framework model. The respondents were from Creative Industry Agency and a creative industry's owner. The interviewees were given informed consent that all data would be confidential and only for academic research purposes.

Creative Economy Agency personnel state that people, as KM enablers, need to be developed to innovate as part of learning and growth. Intellectual capital should be retained through knowledge storage, and creativity will be appreciated as a model for creative industries. In addition, a creative industry's owner explained that several processes in KM strategies, such as knowledge application, help in improving the quality and innovation of an organization's product. 


\section{Conclusion}

This study aims to propose a framework model to formulate the relationship between KM strategies, KM enablers, and learning and growth in creative industries. Although there are few studies related to KM in creative industries, several previous studies in other industries, such as small and medium enterprises, are also analyzed to develop the framework model.

KM enablers, including culture, people, and technology, will promote learning and growth in creative industries (Hussein et al., 2016). KM processes explain the KM processes of knowledge identification, knowledge storage, knowledge sharing, and knowledge application. KM strategies will also influence learning and growth in creative industries (Latilla et al., 2018). The framework model further proposes that KM enablers affect KM strategies.

This literature review is limited to journals included in Mendeley, ProQuest, Publish or Perish, and Google Scholar databases, and the findings are the result of papers obtained through this research. Future research will be conducted in several creative industries to implement the proposed framework model.

\section{References}

Adhiatma, A., Fachrunnisa, O., and Mustafa. (2020), "Digital knowledge supply chain for creative industry: a conceptual framework", Advances in Intelligent Systems and Computing, Vol. 993, pp. 914-924. https://doi.org/10.1007/978-3-030-22354-0_85

Allameh, S. M., Zare, S. M., and Davoodi, S. M. R. (2011), "Examining the impact of KM enablers on knowledge management processes", Procedia Computer Science, Vol. 3, pp. 1211-1223. https://doi.org/10.1016/j.procs.2010.12.196

Andriani, M., Samadhi, T. M. A. A., Siswanto, J., and Suryadi, K. (2019), "Knowledge management strategy: an organisational development approach", Business Process Management Journal, Vol. 25 No. 7, pp. 1474-1490. https://doi.org/10.1108/BPMJ07-2018-0191

Bashouri, J. and Duncan, G. W. (2014). "Communities of practice: linking knowledge management and strategy in creative firms", Journal of Business Strategy, Vol 35 No. 6, pp. 49-57. https://doi.org/10.1108/JBS-08-2013-0072

Bettiol, M., Di Maria, E., and Grandinetti, R. (2012), "Codification and creativity: knowledge management strategies in KIBS", Journal of Knowledge Management, Vol. 16 No. 4, pp. 550-562. https://doi.org/10.1108/13673271211246130

Castagna, F., Centobelli, P., Cerchione, R., Esposito, E., Oropallo, E., and Passaro, R. (2020), "Customer knowledge management in SMEs facing digital transformation", $\begin{array}{lllllll}\text { Sustainability } & \text { (Switzerland), } & \text { Vol. } & 12 & \text { No. } & 9, & \text { p. }\end{array} 3899$. https://doi.org/10.3390/su12093899

Cruz, A. R., Almeida, R. N., Costa, P., Gato, M. A., and Perestrelo, M. (2019), "Knowledge transfer in the cultural and creative sector: institutional aspects and perspectives from actors in selected Atlantic regions", Social Sciences, Vol. 8 No. 3, p. 77. https://doi.org/10.3390/socsci8030077

Data Statistik dan Hasil Survey Ekonomi Kreatif 2016. Retrieved from https://www.kemenparekraf.go.id/asset_admin/assets/uploads/media/pdf/media_1589 841802_Data_Statistik_Hasil_Survei_Ekraf_2016_pdf.pdf

Desouza, K.C. and Awazu, Y. (2006), "Knowledge management at SMEs: five peculiarities", Journal of Knowledge Management. 
Durst, S. and Wilhelm, S. (2011), "Knowledge management in practice: insights into a medium-sized enterprise's exposure to knowledge loss", Prometheus, Vol. 29 No. 1, pp. 23-38.

Evangelista, P., Esposito, E., Lauro, V., and Raffa, M. (2010), "The adoption of knowledge management systems in small firms", Electronic Journal of Knowledge Management, Vol. 8 No. 1, pp. 33-42. Retrieved from www.ejkm (accessed Day Month Year)

Ferraris, A., Vrontis, D., Belyaeva, Z., De Bernardi, P., and Ozek, H. (2020), "Innovation within the food companies: how creative partnerships may conduct to better performances?", British Food Journal. https://doi.org/10.1108/BFJ-07-2019-0502

Galvan, J.S. and Galvan, M.C. (2017). Writing Literature Reviews. Taylor \& Francis.

Gateau, T. and Simon, L. (2016), "Clown scouting and casting at the cirque du soleil: Designing boundary practices for talent development and knowledge creation", International Journal of Innovation Management, Vol. 20 No. 4, pp. 1-31. https://doi.org/10.1142/S1363919616400065

Heavin, C. and Adam, F. (2012), "Characterising the knowledge approach of a firm: an investigation of knowledge activities in five software SMEs. Electronic Journal of Knowledge Management, Vol. 10 No.1, pp. 48-63.

Hotho, S. and Champion, K. (2011), "Small businesses in the new creative industries: innovation as a people management challenge", Management Decision, Vol. 49 No. 1, pp. 29-54. https://doi.org/10.1108/00251741111094428

Jelenic, D. (2011), "The importance of knowledge management in organizations - with emphasis on the balanced scorecard learning and growth perspective", in Management, Knowledge and Learning International Conference 2011, pp. 33-43.

Kaplan, R. S. and Norton, D. P. (1996), Translating Strategy into Action: The Balanced Scorecard, Harvard Business School Press, Boston.

Latilla, V. M., Frattini, F., Petruzzelli, A. M., and Berner, M. (2018), "Knowledge management, knowledge transfer and organizational performance in the arts and crafts industry: a literature review", Journal of Knowledge Management, Vol. 22 No. 6, pp. 1310-1331. https://doi.org/10.1108/JKM-08-2017-0367

Latilla, V. M., Frattini, F., Petruzzelli, A. M., and Berner, M. (2019), "Knowledge management and knowledge transfer in arts and crafts organizations: evidence from an exploratory multiple case-study analysis", Journal of Knowledge Management, Vol. 23 No. 7, pp. 1335-1354. https://doi.org/10.1108/JKM-11-2018-0699

Lee, C. S. and Wong, K. Y. (2015), "Development and validation of knowledge management performance measurement constructs for small and medium enterprises", Journal of Knowledge Management, Vol. 19 No. 4, pp. 711-734. https://doi.org/10.1108/JKM-10-2014-0398

Lee, H. and Choi, B. (2003), "Knowledge management enablers, processes, and organizational performance: an integrative view and empirical examination”, Journal of Management Information Systems, Vol. 20 No. 1, pp. 179-228. https://doi.org/10.1080/07421222.2003.11045756

Ma, L., Qian, C., Liu, Z., and Zhu, Y. (2018), "Exploring the innovation system of the animation industry: case study of a Chinese company", Sustainability (Switzerland), Vol. 10 No. 9, p. 3213. https://doi.org/10.3390/su10093213

Mayasari, Y., and Chandra, T. (2020), "Social capital for knowledge management system of the creative industry", Journal of Enterprising Communities, Vol. 14 No. 4, pp. 481-494. https://doi.org/10.1108/JEC-01-2020-0008

Mansaray, H. (2020). Organizational Strategies and Performance in the Banking Industry Focused on the Transnational Banks in Sierra Leone: An Ex Post Facto Study. 
Budapest International Research and Critics Institute-Journal (BIRCI-Journal). P. 3185-3196

Millar, C. C. J. M., Lockett, M., and Mahon, J. F. (2016), "Guest editorial: knowledge intensive organisations: on the frontiers of knowledge management", Journal of Knowledge Management, Vol. 20 No. 5, pp. 845-857. https://doi.org/10.1108/JKM07-2016-0296

Othman, A. A. E. and Khalil, M. H. M. (2018), "Lean talent management: a novel approach for increasing creativity in architectural design firms", Engineering, Construction and Architectural Management, Vol. 25 No. 10, pp. 1355-1375. https://doi.org/10.1108/ECAM-07-2017-0139

Ruiz, F. J., Agell, N., Angulo, C., and Sánchez, M. (2018), "A learning system for adjustment processes based on human sensory perceptions", Cognitive Systems Research, Vol. 52, pp. 58-66. https://doi.org/10.1016/j.cogsys.2018.06.011

Seidel, S. (2011), "Toward a theory of managing creativity-intensive processes: a creative industries study", Information Systems and E-Business Management, Vol. 9 No. 4, pp. 407-446. https://doi.org/10.1007/s10257-009-0123-7

Stejskal, J. and Hajek, P. (trabucchi2019), "Modelling collaboration and innovation in creative industries using fuzzy set qualitative comparative analysis", Journal of Technology Transfer, Vol. 44 No. 3, pp. 981-1006. https://doi.org/10.1007/s10961017-9638-0

Syardiansah, et al. (2020). The Effect of Job Satisfaction and Organizational Culture on Employee Performance of the Royal Hotel in East Aceh District. Budapest International Research and Critics Institute-Journal (BIRCI-Journal). P. 849-857.

Tassabehji, R., Mishra, J. L., and Dominguez-Péry, C. (2019), "Knowledge sharing for innovation performance improvement in micro/SMEs: an insight from the creative sector", Production Planning and Control, Vol. 30 Nos. 10-12, pp. 935-950. https://doi.org/10.1080/09537287.2019.1582101

Tranfield, D., Denyer, D., and Smart, P. (2003), "Towards a methodology for developing evidence-informed management knowledge by means of systematic review", British Journal of Management, Vol 14 No. 3, pp. 207-222.

Wee, J.C. and Chua, A.Y. (2013), "The peculiarities of knowledge management processes in SMEs: the case of Singapore", Journal of Knowledge Management.

Yeh, Y. J., Lai, S. Q., and Ho, C. T. (2006), "Knowledge management enablers: a case study", Industrial Management and Data Systems, Vol. 106 No. 6, pp. 793-810. https://doi.org/10.1108/02635570610671489 